\title{
Impact of Transformer Design on Flyback Converter Voltage Spikes
}

\author{
Edvardas Bielskis $^{1,2}$, Algirdas Baskys ${ }^{1,3}$, Martynas Sapurov ${ }^{1,3}$ \\ ${ }^{I}$ Center for Physical Sciences and Technology, \\ A. Gostauto 11, LT- 01108 Vilnius, Lithuania \\ ${ }^{2}$ Department of Electronics and Electrical Engineering, Siauliai University, \\ Vilniaus St. 141, LT-76353 Siauliai, Lithuania \\ ${ }^{3}$ Department of Computer Engineering, Vilnius Gediminas Technical University, \\ Naugarduko St. 41, LT-03227 Vilnius, Lithuania \\ edvardas.bielskis@su.lt
}

\begin{abstract}
The transformer design impact on voltage spikes, which arise on the drain of flyback converter MOSFET switch transistor, has been investigated. The special experimental model of flyback transformer was developed. The impact of transformer core air gap, windings design and windings position in transformer bobbin on the voltage spikes was investigated. The ways for reduction of voltage spikes by variation of transformer design were estimated.
\end{abstract}

Index Terms-Flyback transformer; leakage inductance; voltage spikes; air gap.

\section{INTRODUCTION}

The disadvantage of low power switched mode flyback converter is leakage inductance phenomenon of flyback transformer [1]-[3]. It causes increase of voltage spikes generated during the switch commutation. The energy consumed for generation of voltage spikes lowers the efficiency of flyback converter [1]-[8]. The overvoltage clamp circuits have to be employed for spike suppression to avoid the breakdown of switch transistors [3], [5]-[6].

The theoretical analysis or simulation means are used usually for analysis of flyback transformer design impact on voltage spikes [1]-[6]. However, any model cannot take into account all phenomena. Additionally, it is complicated to determine the values of transformer model parameters. Because of this, the accuracy of flyback transformers simulation is limited [1], [5], [9]. Therefore, the experimental investigation means have to be used to obtain accurate results. The purpose of this work is to investigate the impact of flyback transformer design on voltage spikes in converter caused by the leakage inductance. The investigation was performed for cases when transformer windings are placed using interleaving and sandwich methods [1] and two methods proposed by authors.

\section{EXPERIMENTAL MODEL OF FLYBACK TRANSFORMER}

The core of flyback transformer has air gap. Therefore, the flux, which does not link the primary and secondary

Manuscript received 20 December, 2015; accepted 11 May, 2016 windings, is increased relative to the flux that links these windings. Because of this, the link between the primary and secondary windings is weakened [1], [4]. The part of flux that is located outside the core of transformer introduces the leakage inductance, which causes undesirable phenomenon the voltage spikes on the drain of flyback converter MOSFET switch transistor (Fig. 1).

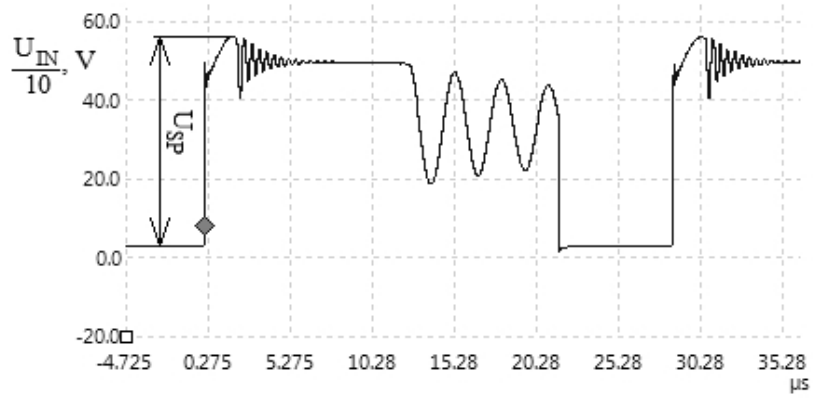

Fig. 1. Transient of drain voltage of flyback converter MOSFET switch transistor.

The leakage inductance is proportional to magnetomotive force between the windings that acts in air gap of core [5] (Fig. 2). Magnetomotive force $F(x)$, which causes leakage magnetic field, depends on geometry of transformer windings

$$
F(x)=H(x) l_{w},
$$

where $H(x)$ is magnetic field strength.

The leakage flux in air gap of core is much lower than flux in core. This happens because the permeability of magnetic core $\mu$ is much higher than air permeability $\mu_{0}$. The $\mu$ decreases and, as a consequence, the leakage inductance increases if the transformer core saturates. The air gap in the core of the flyback transformer weakens the link between windings as well.

The experimental model of transformer was made using ETD-34 type ferrite core with magnetic material N27. The transformer has 15 windings, every winding has 10 turns made of copper conductor with $0.6 \mathrm{~mm}^{2}$ cross-section area (Fig. 3). Such design of transformer allows us to connect the 
windings in various manners according the experimental investigation scenario.

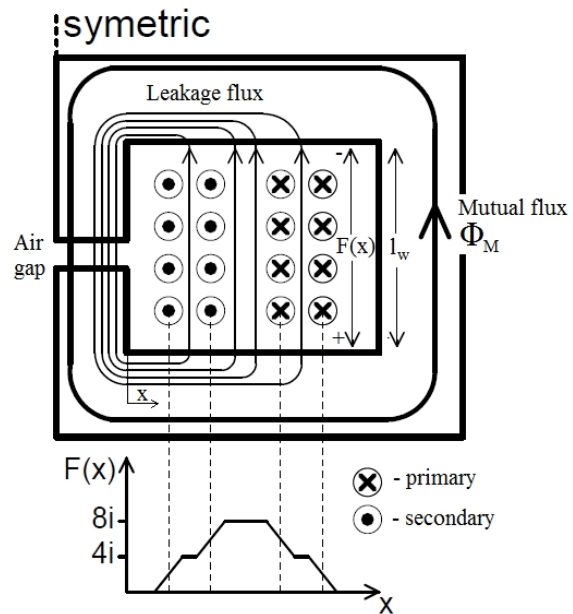

Fig. 2. Variation of magnetomotive force in the half-core window area.

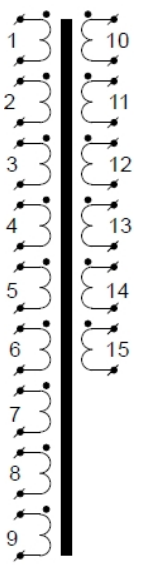

a)

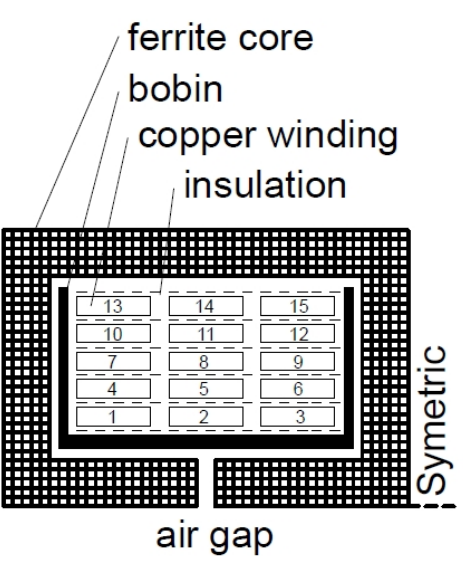

b)
Fig. 3. Design of flyback transformer experimental model: a) circuit diagram of windings; $b$ ) windings of the bobbin.

The measured value of one winding inductance versus core air gap is given in Table I.

TABLE I. INDUCTANCE OF ONE WINDING MEASURED AT THE DIFFERENT AIR GAP DIMENSIONS

\begin{tabular}{|c|c|}
\hline Air gap, $\mathbf{~ m m}$ & Inductance, $\boldsymbol{\mu H}$ \\
\hline 0,0 & 235 \\
\hline 0,2 & 62 \\
\hline 0,7 & 33 \\
\hline 1,0 & 25 \\
\hline 2,0 & 19 \\
\hline
\end{tabular}

\section{INVESTIGATION OF FLYBACK TRANSFORMER DESIGN IMPACT ON VOLTAGE SPIKES}

The investigation was carried out for the DC-DC flyback converter. Circuit diagram of converter experimental model with passive overvoltage clamp circuit is presented in Fig. 4. Controller of DC-DC flyback converter stabilizes the output voltage using feedback control. The desirable values of output voltage and switching frequency can be set.

The parameters of DC-DC flyback converter components are presented in Table II.

The dependence of converter switch transistor Q1 drain voltage spikes on converter output power at various transformer core (Fig. 3) air gap dimensions was investigated. The results were obtained for $0 \mathrm{~mm}$ (without air gap), $0.2 \mathrm{~mm}, 0.7 \mathrm{~mm}, 1 \mathrm{~mm}, 1.5 \mathrm{~mm}$ and $2 \mathrm{~mm}$ air gap, for $16 \mathrm{~V}$ output voltage and $35 \mathrm{kHz}$ switching frequency. The investigation was carried out for the transformer windings connection variant number 4 (Table III). The obtained investigation results are presented in Fig. 5.

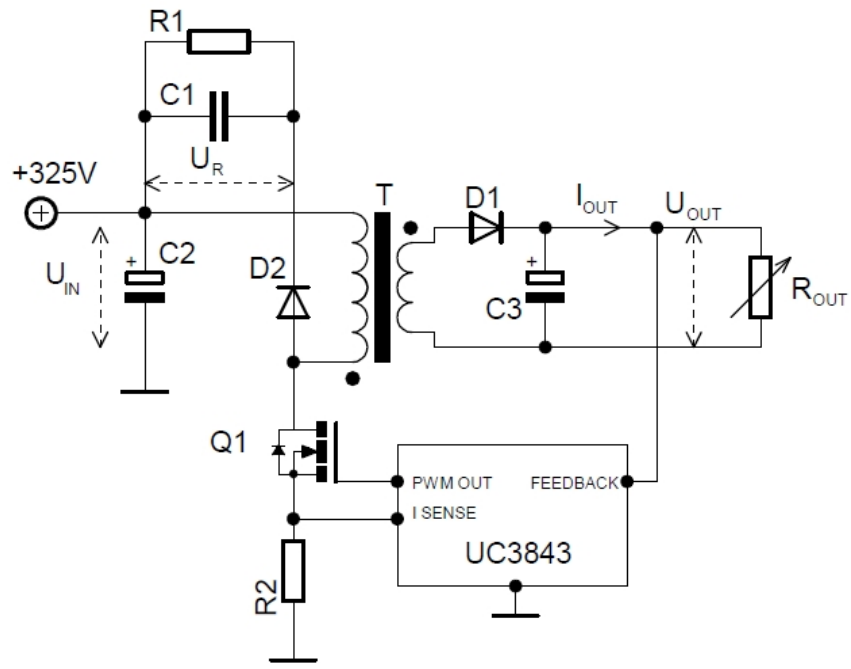

Fig. 4. Circuit diagram of flyback DC-DC converter experimental model.

TABLE II. PARAMETERS OF DC-DC FLYBACK CONVETER COMPONENTS.

\begin{tabular}{|c|c|}
\hline Electronic component & Parameter value \\
\hline C1 (clamp capacitor) & $10 \mathrm{nF} \times 450 \mathrm{~V}$ \\
\hline C2 (input capacitor) & $1200 \mu \mathrm{F} \times 400 \mathrm{~V}$ \\
\hline C3 (output capacitor) & $4700 \mu \mathrm{F} \times 35 \mathrm{~V}$ \\
\hline R1 (clamp resistor) & $3.3 \mathrm{~K} \Omega, 10 \mathrm{~W}$ \\
\hline R2 (current sensing) & $0.22 \Omega, 2 \mathrm{~W}$ \\
\hline Q1 (main switch) & $\mathrm{K} 2717(900 \mathrm{~V}, 5 \mathrm{~A})$ \\
\hline D1 (output rectifier) & MUR1560 $(600 \mathrm{~V}, 15 \mathrm{~A})$ \\
\hline D1 (clamp rectifier) & $\mathrm{BY} 228(1500 \mathrm{~V}, 5 \mathrm{~A})$ \\
\hline
\end{tabular}

TABLE III. TRANSFORMER WINDINGS CONNECTION VARIANTS.

\begin{tabular}{|c|c|c|c|}
\hline $\begin{array}{c}\text { Variant } \\
\text { number }\end{array}$ & $\begin{array}{c}\text { Quantity of } \\
\text { parallel } \\
\text { connected } \\
\text { windings, } \\
\text { which form } \\
\text { secondary } \\
\text { winding }\end{array}$ & $\begin{array}{c}\text { Numbers of } \\
\text { parallel } \\
\text { connected } \\
\text { windings, which } \\
\text { form secondary } \\
\text { winding }\end{array}$ & $\begin{array}{c}\text { Numbers of } \\
\text { windings } \\
\text { connected in } \\
\text { series, which } \\
\text { form primary } \\
\text { winding }\end{array}$ \\
\hline 1 & 1 & 4 & $1,2,3,7,8,9$ \\
\hline 2 & 2 & 4,5 & $1,2,3,7,8,9$ \\
\hline 3 & 3 & $4,5,6$ & $1,2,3,7,8,9$ \\
\hline 4 & 6 & $4,5,6,7,8,9$ & $1,2,3,10,11,12$ \\
\hline 5 & 9 & $4,5,6,7,8,9,10$, & $1,2,3,13,14,15$ \\
\hline
\end{tabular}

It is seen that output power of converter, at which ferrite core of transformer saturates, increases with air gap width. For the output power up to $120 \mathrm{~W}$ the lowest voltage spikes are reached when the transformer core gap is $0.7 \mathrm{~mm}$. The magnetic field leakage phenomena come into play stronger when the transformer core gap increases significantly. Therefore, the voltage spikes at $1 \mathrm{~mm}$ and $2 \mathrm{~mm}$ core gap are higher as compared to the case when $0.7 \mathrm{~mm}$ gap is used (Fig. 5)

The dependence of voltage spikes on quantity of parallel connected windings, which form secondary winding, was investigated. The investigation was performed for $16 \mathrm{~V}$ converter output voltage, $35 \mathrm{kHz}$ switching frequency and $1 \mathrm{~mm}$ transformer core air gap. The investigated transformer primary and secondary windings connection variants are 
given in Table III. The obtained results are presented in Fig. 6.

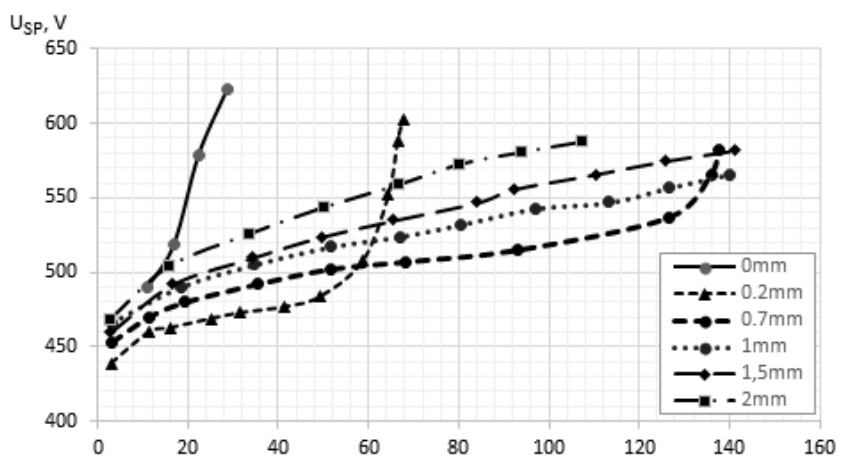

Fig. 5. The dependences of voltage spikes on flyback converter output power at various transformer core air gap dimensions at $35 \mathrm{kHz}$ switching frequency.

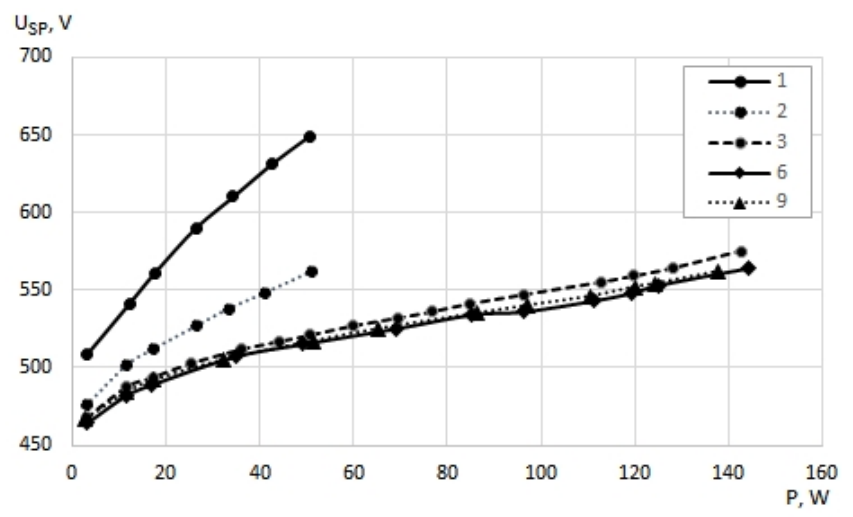

Fig. 6. The dependences of voltage spikes on flyback converter output power at various quantities of parallel connected windings (Table III), which form secondary winding of transformer, at $1 \mathrm{~mm}$ core air gap and 35 $\mathrm{kHz}$ switching frequency.

It is seen that parallel connection of windings, which form secondary winding of transformer, allows us decrease the voltage spikes. The voltage spikes decreases from $650 \mathrm{~V}$ to $565 \mathrm{~V}$ at $50 \mathrm{~W}$ output power when instead of one winding two parallel connected windings are used. The connection of third winding allows reducing the voltage spikes up to $520 \mathrm{~V}$. However, the further increase of parallel connected windings quantity does not influence the value of voltage spikes significantly.

The voltage spike reduction phenomena can be explained by the fact that in case when only one winding is used, the magnetomotive force in air gap between primary and secondary windings (Fig. 2) is damped weakly by the secondary winding. This happens because the secondary winding is on the edge of bobbin (Fig. 3(b)) and damps only the magnetomotive force created by the 1 and 7 windings, therefore, the magnetomotive forces developed by the 2, 3, 8 and 9 windings are not damped, because of this, the leakage inductance and, as a consequence, the voltage spikes in primary winding, increase. If the secondary winding is created using three in parallel connected windings, the primary windings of transformer are covered by secondary windings (Fig. 3(b)). Therefore, the flux, which links the primary and secondary windings and, as a consequence, the link between the primary and secondary windings increases decreasing the leakage inductance.

The obtained results (Fig. 6) show that employment of secondary winding in flyback transformer using parallel connected windings reduces the voltage spikes by $25 \%$ and voltage overshoot by $67 \%$ at $50 \mathrm{~W}$ output power. Therefore, the power losses caused by the overshoot dissipated in passive clamp circuit and, as a consequence, the power losses of flyback converter are reduced.

The impact of windings location in transformer bobbin on flyback converter voltage spikes was investigated. The investigation was performed for $16 \mathrm{~V}$ converter output voltage, $35 \mathrm{kHz}$ switching frequency and $1 \mathrm{~mm}$ transformer core air gap. The investigation was performed for seven transformer primary and secondary windings connection (location in transformer bobbin) variants. The connection variants of windings are given in Table IV. It is seen that in all variants the secondary winding is formed using six in parallel connected windings, however, the location of windings in various variants was different. In the similar way, the various variants of serial connection of windings used for forming of primary winding were investigated. The obtained results are presented in Fig. 7.

TABLE IV. TRANSFORMER WINDINGS CONNECTION VARIANTS.
\begin{tabular}{|c|c|c|}
\hline $\begin{array}{l}\text { Variant } \\
\text { number }\end{array}$ & $\begin{array}{c}\text { Numbers of parallel } \\
\text { connected windings, } \\
\text { which form secondary } \\
\text { winding }\end{array}$ & $\begin{array}{c}\text { Numbers of windings } \\
\text { connected in series, which } \\
\text { form primary winding }\end{array}$ \\
\hline 1 & $7,8,9,10,11,12$ & $1,2,3,4,5,6$ \\
\hline 2 & $1,2,3,4,5,6$ & $7,8,9,10,11,12$ \\
\hline 3 & $1,2,3,10,11,12$ & $4,5,6,7,8,9$ \\
\hline 4 & $4,5,6,7,8,9$ & $1,2,3,10,11,12$ \\
\hline 5 & $4,5,6,10,11,12$ & $1,2,3,7,8,9$ \\
\hline 6 & $1,3,5,7,9,11$ & $2,4,6,8,10,12$ \\
\hline 7 & $1,4,5,7,10,11$ & $2,3,6,8,9,12$ \\
\hline
\end{tabular}

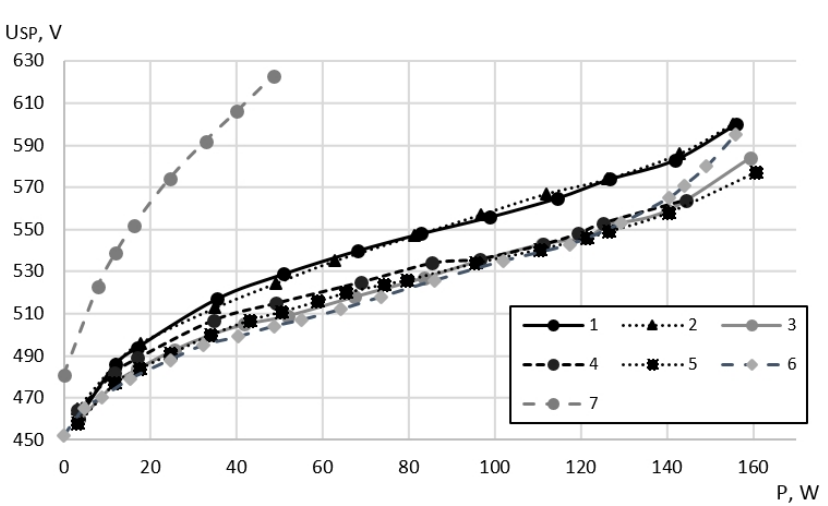

Fig. 7. The dependences of voltage spikes on flyback converter output power for transformer windings connection variants 1-7 (Table IV) at $1 \mathrm{~mm}$ core air gap and $35 \mathrm{kHz}$ switching frequency.

In the case when transformer windings connection is performed using 1 (the primary winding is under the secondary winding (Fig. 3)) and 2 (the primary winding is over the secondary winding (Fig.3)) variants (Table IV), the overvoltage is higher as compared to the 3 and 4 variants (interleaving method), 5 variant (sandwich method). This happens because in case of interleaving and sandwich placing methods of windings the leakage inductance is lower as compared to the 1 and 2 variants.

The two placing methods of windings proposed by authors: chess interleaving (variant 6, Table IV) method and method when primary and secondary windings are concentrated at the borders of bobbin (variant 7, Table IV) 
have been investigated as well. The obtained results show (Fig. 7) that variant 6 provides slightly lower spikes as compared to 3-5 variants at power up to $120 \mathrm{~W}$. However, the results become worse at higher power. The highest spikes are generated in case when windings are placed using variant 7 (Fig. 7).

The energy of overshoot, which arises during the voltage spike (Fig. 1) is dissipated in the resistor of passive clamp circuit R1. Additionally, the power caused by the output voltage reflected to the primary winding is dissipated in resistor R1. The reflected voltage $\left(U_{\mathrm{RO}}\right)$ appears when the diode D1 (Fig. 4) conducts the current of the secondary winding. $U_{\mathrm{RO}}$ delivers additional energy to clamp circuit resistor R1. $U_{\mathrm{RO}}$ can be calculated using equation

$$
U_{\mathrm{RO}}=\left(U_{\mathrm{OUT}}+U_{\mathrm{D}}\right) \frac{n_{\mathrm{pri}}}{n_{\mathrm{sec}}},
$$

where $U_{\mathrm{D}}$ is voltage drop across forward biased diode D1, $n_{\text {pri }}$ and $n_{\text {sec }}$ are number of primary and secondary windings turns, respectively. It is seen that at constant $U_{\text {OUT }}$ the $U_{\text {RO }}$ is constant, i.e. the power dissipation in $\mathrm{R} 1$ caused by reflected voltage $\left(P_{\text {REFL }}\right)$ is constant.

The total power dissipated in the resistor $\mathrm{R} 1$ can be obtained by measurement of integral value of voltage drop across the resistor $U_{\text {Rint }}$ and calculating of power losses by following equation

$$
P_{\text {TOT }}=\frac{U_{\text {Rint }}^{2}}{R_{1}} .
$$

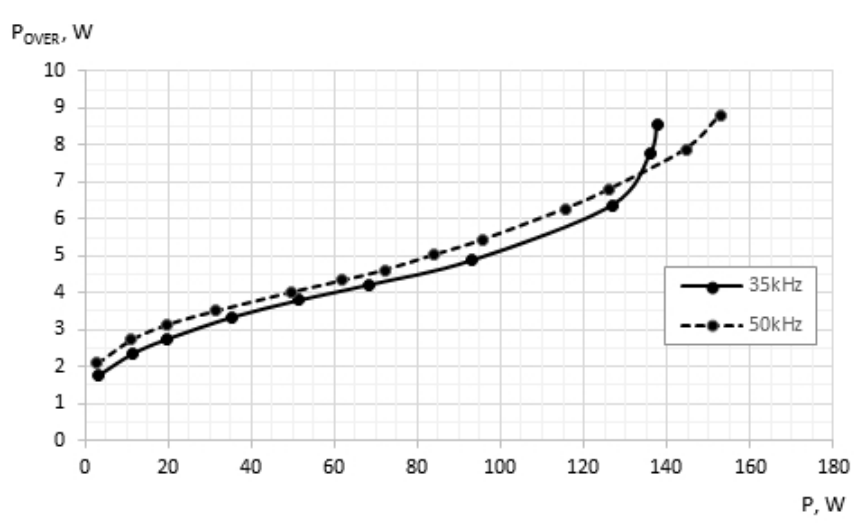

Fig. 8. The dependence of power losses caused by the voltage overshoot dissipated in passive clamp circuit resistor R1. The core air gap $0.7 \mathrm{~mm}$, switching frequency $35 \mathrm{kHz}$ and $50 \mathrm{kHz}$.

The power caused by the overshoot, which is dissipated in passive clamp circuit resistor $\mathrm{R} 1$, is obtained as difference $P_{\text {OVER }}=P_{\text {TOT }}-P_{\text {REFL }}$. The dependence of power losses caused by the overshoot on flyback converter output power for the situation when core air gap width is $0.7 \mathrm{~mm}$, switching frequency $35 \mathrm{kHz}$ and $50 \mathrm{kHz}$ are presented in Fig. 8. It is seen that the power losses in clamp circuit resistor R1 increases with the output power and are slightly higher at higher switching frequency.

It is seen that law of dependence of power losses caused by the voltage overshoots (Fig. 8, curve that corresponds to $35 \mathrm{kHz}$ ) and law of voltage spikes dependence (Fig. 5, curve that corresponds to $0.7 \mathrm{~mm}$ air gap) on converter output power coincide. This fact supports the proposition that power losses presented by the curves given in Fig. 8 are caused by the voltage overshoots.

\section{CONCLUSIONS}

The enlargement of flyback transformer core air gap reduces the converter switch transistor drain voltage spikes, which become minimal at $0.7 \mathrm{~mm}$ air gap. However, at larger dimension of air gap the voltage spikes increase because the magnetic field leakage phenomena come into play stronger.

The parallel connection of windings, which form secondary winding of transformer, allows us decrease the voltage spikes from $650 \mathrm{~V}$ to $520 \mathrm{~V}$ at $50 \mathrm{~W}$ output power when instead of one winding three parallel connected windings are used.

The proposed chess interleaving placing method of flyback transformer windings provides lowest spikes at power up to $120 \mathrm{~W}$ as compared to another investigated methods.

\section{REFERENCES}

[1] Z. Ouyang, J. Zhang, W. G. Hurley, "Calculation of leakage inductance for high-frequency transformers", IEEE Trans. on Power Electronics, vol. 30, no. 10, pp. 5769-5775, 2015. [Online] Available: http://dx.doi.org/10.1109/TPEL.2014.2382175

[2] D. Leuenberger, J. Biela, "Accurate and computationally efficient modeling of flyback transformer parasitics and their influence on converter losses", in Conf. Power Electronics and Applications 17th European Conf., 2015, pp. 1-10. [Online]. Available: http://dx.doi.org/10.1109/EPE.2015.7309194

[3] R. Radvan, B. Dobrucky, M. Frivaldsky, P. Rafajdus, "Modelling and design of HF $200 \mathrm{kHz}$ transformers for hard- and soft-switching application", Elektronika Ir Elektrotechnika, no. 4, pp. 7-12, 2011 [Online]. Available: http://dx.doi.org/10.5755/ j01.eee.110.4.276

[4] F. A. Holguin, R. Prieto, R. Asensi, J. A. Cobos, "Power losses calculations in windings of gapped magnetic components: The i2D method applied to flyback transformers", in IEEE Conf. Energy Conversion Congress and Exposition (ECCE 2015), pp. 5675-5681. [Online]. Available: http://dx.doi.org/10.1109/ECCE.2015.7310457

[5] L. Zengyi, C. Wei, "Novel winding loss analytical model of flyback transformer", in 37th IEEE Conf. 2006 Power Electronics Specialists Conf., (PESC 2006), pp. 1-6. [Online]. Available: http://dx.doi.org/10.1109/PESC.2006.1711938

[6] R. Sul, B. Dobrucky, P. Cernan, "Evaluation of efficiency of active clamp dual flyback inverter for photovoltaic systems using simulation method", Elektronika Ir Elektrotechnika, vol. 99, no. 3, pp. 23-26, 2010 .

[7] M. Kim, S. Choi, "A fully soft-switched single switch isolated DCDC converter", IEEE Trans. on Power Electronics, vol. 30, pp. 4883-4890, 2015. [Online]. Available: http://dx.doi.org/10.1109/ TPEL.2014.2363830

[8] K. Soltanzadeh, H. Khalilian, M. Dehghani, "Analysis, design and implementation of a zero voltage switching two-switch CCM flyback converter", IET Circuits, Devices \& Systems, vol. 10, pp. 20-28, 2016. [Online]. Available: http://dx.doi.org/10.1049/ietcds.2014.0329

[9] M. A. Pagliosa, T. B. Lazzarin, I. Barbi, "Output characteristics of two-switch flyback including the leakage inductance", in Conf. 2015 IEEE 13th Brazilian Power Electronics and 1st Southern Power Electronics, pp. 1-5. [Online]. Available: http://dx.doi.org/ 10.1109/COBEP.2015.7420077 